\title{
Las luchas contra el delito y sus efectos en la Argentina. Sobre la expansión del encarcelamiento y las dificultades de seguir a nuestros presos ${ }^{*}$
}

DOI: https://doi.org/10.18046/recs.i31.3717

\begin{abstract}
The Struggles against Crime and its Effects in Argentina. On the Expansion of Imprisonment and the Difficulties of Following our Prisoners
\end{abstract}

\section{Inés Mancini**}

Universidad Nacional de San Martín/CONICET (Buenos Aires, Argentina)

\footnotetext{
${ }^{*}$ Este artículo es producto del financiamiento que recibe la autora como investigadora adjunta del CONICET. Además, se utilizan datos de una investigación financiada por el Observatorio de Seguridad Ciudadana de la Universidad de Avellaneda. Artículo de investigación recibido el 18.09.2019 y aceptado el 01.04.2020.

** Dra. en Antropología Social por la Universidad Nacional de San Martín (Argentina).Correo electrónico:inesmmancini@ gmail.com. ORCID: https://orcid.org/oooo-0oo2-8106-5863
} 


\section{Cómo citar/How to cite}

Mancini, Inés (2020). Las luchas contra el delito y sus efectos en la Argentina. Sobre la expansión del encarcelamiento y las dificultades de seguir a nuestros presos. Revista CS, 31, 139-157. https://doi.org/10.18046/recs.i31.3717 


\section{Resumen}

El presente artículo pretende mostrar algunos de los efectos extendidos del encarcelamiento. Se entiende que frente a los discursos punitivistas que circulan en la región latinoamericana, una de las soluciones que los gobiernos proponen y las sociedades aceptan se relaciona con el encarcelamiento. Sin embargo, pocas veces se piensa que la cárcel produce efectos que se extienden mucho más allá de los penados. En este sentido, el incremento de la tasa de encarcelamiento y la selectividad del sistema penal producen una configuración socioterritorial de vinculaciones entre pobreza, justicia y cárcel. Se observan entonces barrios populares cuyos habitantes transitan y habitan juzgados y penales en distintas modalidades (tales como visitantes, cuidadores o detenidos). Así, nos encontramos con barrios populares donde los jóvenes encuentran la prisión como destino posible, al tiempo que muchas de las mujeres afrontan la tarea de cuidarlos, para lo cual deben enfrentarse a las instituciones.

PALABRAS CLAVE:

cárceles, mujeres, familiares

This article aims to show some of the widespread effects of imprisonment. Considering fear of crime, imprisonment is one of the main solution that governments propose and societies accept. However, it is seldom thought that prison produces effects that extend well beyond those convicted. Accordingly, the increase in the incarceration rate and the selectivity of the penal system produces a socio-territorial configuration of links between poverty, justice, and imprisonment. Thus, popular neighborhoods whose inhabitants go to and inhabit in courts and prisons in various ways (as visitors, caregivers, or detainees). Thus, we find young men from popular neighborhoods that find prison as a possible destination and, at the same time, the women from these neighborhoods are supposed to take care of those young people incarcerated.

\section{KEYWORDS:}

Prisons, Women, Relatives 



\title{
Discursos punitivistas, demandas y políticas de seguridad
}

\author{
"Vos vas a los tribunales y te verduguean es como que vos tenés \\ la culpa, los familiares también tenemos la culpa. La cárcel \\ es para todos, sean o no culpables"'. \\ (Madre de dos hijos presos, nota de campo, comunicación \\ personal, 03.12.2018)
}

En la Argentina, desde mediados de la década de 1980 la preocupación por el delito se ha expandido de forma gradual, hasta instalarse entre los principales problemas percibidos por la población (Kessler, 2009); de hecho, en 2008 fue señalado como el principal en el país, al igual que en América Latina. Este incremento de la preocupación se enmarca en un crecimiento objetivo del delito, lo cual es desaprobado por la opinión pública, aunque se argumente que esas tasas son bajas en comparación con otros países de la región. En este sentido se postula la existencia de un descontento creciente (Kessler, 2011).

Aunque el vínculo entre temor y autoritarismo pueda parecer lógico, la extensión del temor a muchos sectores de la población impone nuevas reacciones y demandas de la sociedad para resolver el problema de la seguridad (Kessler, 2011). En este sentido, los gobiernos tienen a su cargo la producción de respuestas a este descontento de la población. Entre esas respuestas, el encarcelamiento es una variable que merece ser atendida. Así, las propuestas políticas involucran discursos y prácticas de abordaje de la delincuencia que pueden hacer más o menos énfasis en el punitivismo.

Ahora bien, es preciso advertir que las conexiones entre discursos (progresistas, neoliberales, punitivistas, etc.) y políticas no son automáticas. Por el contrario, si nos atenemos a observar las tasas de encarcelamiento -una de las respuestas posibles de estos discursos punitivistas-, notamos que en años en los que la Argentina se encuentra en un momento social y político que discute los fundamentos del neoliberalismo, dicho indicador aumenta (Sozzo, 2016).

Asimismo, en tanto y en cuanto las sociedades incluyen a una multiplicidad de actores diversos que experimentan de distintas formas la sensación de inseguridad y son afectados de diversas maneras por el punitivismo, es menester señalar que no hay un solo resultado respecto de los efectos de los castigos, sino que estos se distribuyen de desigual manera en la sociedad, así como hay una distribución desigual sobre los fenómenos de la inseguridad y las apreciaciones sobre las instituciones. Entonces,

1. En el artículo se usarán itálicas para resaltar los términos nativos. 
nuestra propuesta consiste en analizar, a partir de una mirada microscópica cómo opera el impacto del encarcelamiento a escala local. Ello implica detenernos de modo fundamental en dos trabajos de campo: un estudio realizado en una villa de emergencia en la provincia de Buenos Aires; y un trabajo prolongado de seguimiento a allegados de detenidos en diversas cárceles de la Argentina vinculados a una asociación de familiares.

En un trabajo reciente, Focas y Galar (2019) señalan que el gobierno actual de la Argentina (2015-2019) ${ }^{2}$ muestra una "notable comodidad a la hora de hablar y accionar" en la temática de la inseguridad. Así, pese a los cuestionamientos que parte de la sociedad ha manifestado contra las políticas vinculadas a las fuerzas de seguridad, este gobierno ha mostrado como logros de gestión algunos fenómenos que otros sectores de la sociedad han considerado atropellos a las libertades. Ahora bien, estos logros de gestión son valorados por algunos actores 3 . Tal como lo notan Focas y Galar (2019) al analizar un diverso colectivo de la marcha "Para que no te pase", existe la percepción de que los gobiernos anteriores privilegiaron las garantías y derechos de los delincuentes mientras condenaron a las víctimas al ostracismo. Entonces, esta temática de la seguridad y su agenda involucran a diversos actores con una variedad de demandas, derechos que se tensionan y que son representados como si fueran un juego de suma cero: para que los ciudadanos decentes tengan más derechos, sería preciso quitárselos a los otros.

De forma paralela, nuestros trabajos de campo entre sectores populares muestran que muchas de las personas consideran que se producen excesivas detenciones en los barrios y vinculan esta situación con el exceso de preocupación por la inseguridad de otros sectores sociales más favorecidos. Desde su perspectiva, las personas de clases medias o altas establecerían una vinculación automática entre pobreza y delito.

Ese mecanismo circular entre demandas ciudadanas, política y medios de comunicación (Sozzo, 2007) opera convergiendo hacia un incremento en las libertades de acción de las fuerzas de seguridad, y hacia la producción de leyes que restringen las salidas de la prisión que aceleran y adelantan las condenas, al mismo tiempo que los medios de comunicación y el poder ejecutivo demandan al poder judicial un endurecimiento de las condenas y la restricción casi total de las salidas anticipadas de la prisión. Si bien las políticas de seguridad (y sus efectos) del gobierno que inició

2. Nos referimos al gobierno de Mauricio Macri a partir del establecimiento de una alianza política que implicó una alternancia de signo político con los gobiernos precedentes.

3. Nos referimos a la exhibición de incautación de drogas, a la incorporación de tecnologías a las fuerzas de seguridad y a distintos modos en los que el gobierno publicitaba su efectividad en términos de seguridad. 
en 2015 no implicaron una ruptura con lo que ocurría en los gobiernos anteriores, es posible identificar una profundización de la erosión de las libertades civiles.

Así, durante este periodo es posible observar una erosión de las libertades civiles (Lancaster, 2011). Si bien es cierto que estas degradaciones afectan a toda la sociedad, se materializan y se ejercen todos los días de manera desigual. Las fuerzas policiales actúan con mayor capacidad y producen más detenciones en ciertos barrios y lugares (como estaciones de trenes) frecuentados por los sectores populares. De este modo, son las personas con menos recursos materiales y simbólicos quienes deben enfrentar esta erosión de sus libertades.

En efecto, tanto las acciones de las fuerzas policiales como las del poder judicial contribuyen a la producción del incremento del encarcelamiento. Este crecimiento sistemático de la tasa de encarcelamiento se explica por estas acciones, pero también por las miradas de otros poderes o de la opinión pública sobre su accionar. Así, el crecimiento del encarcelamiento ha llegado a un punto crítico en la Argentina, en especial en la provincia de Buenos Aires. En efecto, según datos del Instituto Nacional de Estadística y Censo (Indec), en el año 2013 había 64288 y ese número creció a 94883 en 2018.

En este sentido, el gobierno nacional ha declarado la emergencia penitenciaria reconociendo una sobrepoblación excesiva. Y es crucial señalar que este fenómeno es entendido por el gobierno de Mauricio Macri como un producto indeseado de una gestión exitosa:

El Gobierno explicó que la superpoblación penitenciaria se debe a "las políticas exitosas de seguridad pública y, consecuentemente, de persecución del delito para combatir la inseguridad ciudadana y el crimen organizado" y adelantó que la cantidad de presos "seguirá incrementándose sustancialmente durante el año en curso, proyectándose un crecimiento sostenido de la población carcelaria”. (Infobae, 2019)

Entonces, frente a las demandas de algunos sectores sociales, una de las respuestas posibles ha sido la de mostrar acción incrementando el número de detenidos alojados en las cárceles.

Al mismo tiempo, es preciso notar que las instituciones que tienen a su cargo el trabajo sobre el delito reciben un alto cuestionamiento por parte de diversos sectores sociales. Así, tanto la policía como la justicia y las instituciones penitenciarias son consideradas corruptas o ineficientes; sin embargo, sobre ellas siguen recayendo las demandas de restitución del orden social.

Para presentar esta reflexión, y como se expuso anteriormente, se recurrirá a datos provenientes de dos fuentes diferentes: de un lado, un estudio realizado en un barrio popular en el sur del Gran Buenos Aires, en el marco del cual se realizaron 30 
entrevistas en profundidad a distintos actores, vecinos varones y mujeres, jóvenes y adultos, referentes territoriales y profesionales que se desempeñan en escuelas o centros de atención médica. Este estudio consistió en la realización de entrevistas en profundidad sobre diversos problemas del barrio, con especial énfasis en la seguridad ciudadana ${ }^{4}$. El trabajo de campo fue realizado durante el año 2016. Y de otro lado, una investigación de largo plazo que se viene realizando desde hace cuatro años en la Asociación Civil de Familiares de Detenidos (Acifad). Allí se realizó observación participante de las reuniones, así como también historias de vida y entrevistas a muchas de sus participantes. El trabajo de campo comenzó en el año 2015 y continúa hasta la actualidad.

\section{Las cárceles como solución al problema de la inseguridad}

Señalar que las instituciones deberían funcionar adecuadamente para resolver el problema de la seguridad es moneda corriente. ¿Pero qué significa este funcionamiento adecuado y cómo resolvería el problema del incremento de los delitos que preocupan a la población? Con frecuencia, cuando la cárcel es pensada desde la distancia se entiende que una persona encarcelada es una menos para cometer delitos aberrantes.

Por ejemplo, Focas y Galar (2019) resumen las demandas de los ciudadanos que participan de una marcha pidiendo seguridad; entre ellas se encuentra la de "cumplimiento efectivo de las penas". Esta resulta consistente respecto de un argumento esgrimido con frecuencia en los medios de comunicación que podría resumirse en que, luego de relatar algún delito aberrante, se señalan los antecedentes de su autor y se busca culpabilizar a las instituciones para sostener, por ejemplo, que el delincuente gozó de una libertad anticipada (libertad condicional, asistida, etc.) de acuerdo con lo previsto por la ley. En este sentido, se demanda a las instituciones (penitenciaria y judicial) la facultad de predecir el comportamiento del delincuente para sostener el encarcelamiento.

Ahora bien, la investigación ha demostrado con creces que no existe una correspondencia automática entre el incremento en tasas de delitos y de encarcelamiento. Pese a reconocerse que la cárcel ha demostrado no ser efectiva en la resocialización de los detenidos, se sigue recurriendo a ella y se enfatiza en el endurecimiento de penas, pues la prisión es utilizada como un mecanismo de resolución de problemas

4. El estudio fue realizado en el marco del Observatorio de Seguridad Ciudadana de la Universidad Nacional de Avellaneda. 
sociales (Mathiesen, 2003) que muestra a las autoridades políticas como responsables activas en la solución del problema de la seguridad (Bauman, 1999).

(...) la devaluación de una persona que está en el centro del sistema penal, ya sea como delincuente o como recluso (términos que el público suele considerar sinónimos) se relaciona con el incremento de la cantidad de personas que entran dentro de estas categorías. Existe una afinidad entre los procesos sociales que generan un aumento en el número de presos y de aquellos que cambian -para peor- la representación del delincuente. (Melossi, 2018: 24)

En este orden de cosas, la demanda por más cárcel (para más gente y por más tiempo) es pensada como una medida que, mediante el aislamiento de algunos que según lo antedicho serían personas devaluadas, protege a otros.

Si la misión resocializadora de la prisión ha fracasado, debemos preguntarnos por la persistencia de esta práctica de sacar de circulación a este sector social. En este sentido, Tonkonoff (2012) habla del "alma de la pena". Así, postula que esta última es un acto colectivo destinado a establecer alteridad, a definir otro; en este acto se constituye -por exclusión- un colectivo moral.

De forma contraria a las nociones de la cárcel como aislamiento, las miradas etnográficas muestran un flujo constante y permanente de relaciones que Ferreccio (2017), Mancini (2018) y Pereyra Iraola (2017) involucran antes, durante y después de las condenas a los presos con sus familiares y allegados. En este sentido, la combinación del incremento de la tasa de encarcelamiento con la selectividad del sistema penal produce una configuración socioterritorial de vinculaciones entre pobreza, justicia y cárcel. Se observan entonces barrios populares cuyos habitantes transitan y habitan en distintas modalidades (como visitantes, cuidadores o detenidos) juzgadas y penales. Así, la cárcel se convierte en un actor más en las interacciones cotidianas de los barrios y en las familias de sectores populares. Esta participación y relación cotidiana con la cárcel produce efectos concretos que agravan la situación de la seguridad.

\section{Barrios, sectores populares y cárcel}

Aunque en los medios de comunicación las relaciones entre agenda de inseguridad y barrios populares apuntan, en ocasiones, a describir estos lugares como ámbitos donde hay poco alcance estatal, y como ambientes propicios para alojar y reproducir el delito, cualquier investigación etnográfica sobre la vida en un barrio popular y la inseguridad muestra la preocupación y la vivencia de los habitantes y trabajadores de estos barrios de una manera similar a otros espacios de las ciudades. 
En el estudio realizado en una villa de emergencia en el sur de la provincia de Buenos Aires se aprecia que los entrevistados señalan estar preocupados por la temática de la seguridad en el barrio. Se trata de un problema que se ha vuelto acuciante desde hace poco tiempo, aunque no se pueda precisar con exactitud un punto de inflexión (para algunos, entre 10 y 15 años; para otros es más reciente). Incluso no es posible registrar coincidencias en las periodizaciones construidas por los entrevistados que sí se encuentran en posición de registrar un momento. Antes bien, todos refieren a un momento -tal vez mítico- en el que las cosas en el barrio eran de otro modo. Se reconoce, entonces, que se trata de una problemática que se caracteriza por fluctuaciones: esto es, momentos de mayor y menor incidencia (Mancini; Rey, 2017).

Por otra parte, tanto los entrevistados habitantes del barrio como los profesionales que trabajan allí coinciden en señalar a los jóvenes como actores fundamentales en la producción de estos delitos. Asimismo, vinculan el consumo de drogas con ellos. En este sentido, buena parte de las demandas que tanto unos como otros hacen a las instituciones consisten en la prevención social, que encuentra eco en ciertos programas sociales que tienen lugar con los jóvenes del barrio. Como lo sostiene Vázquez (2015), al margen de las retóricas no punitivas de las intervenciones estatales de corte social, la juventud es construida en relación con una condición social asociada a la disponibilidad al delito.

En la medida en que se trata de un barrio en el que priman las relaciones cara a cara en las interacciones cotidianas, estos jóvenes son conocidos por vecinos y trabajadores del barrio. Así, identifican a ciertos grupos de jóvenes y son señalados como problemáticos. En este punto es importante destacar que estos discursos ponen las fuerzas de seguridad en una posición compleja, puesto que este saber respecto de determinados vecinos y sus transgresiones a la ley no se plasma en denuncias formales.

De este modo, lo que se desprende de las entrevistas realizadas es que el accionar que de manera velada o directa se reclama a la policía se funda en rumores. Por lo tanto, si la policía accionara a partir de los mismos, probablemente sería reprobada. En consecuencia, aparecen relatos sobre la intervención de los propios vecinos en la resolución de los problemas causados por estos menores o jóvenes que cometen delitos en el barrio: una vecina cuenta que "los fajaron los vecinos" en alguna ocasión, ante la sensación de fastidio e inacción de las fuerzas de seguridad, "la policía no hace nada" (Mancini; Rey, 2017).

Frente al conocimiento del origen de los problemas, vecinos y trabajadores hacen cuestionamientos a las instituciones: en concreto, a las fuerzas de seguridad y a la justicia, señaladas como ineficientes por cuanto no hacen nada frente a una situación conocida por todos. Evidentemente, los cuestionamientos se dirigen con mucha más 
fuerza a la policía, que a diferencia de la justicia es un actor visible en el barrio. Las fuerzas de seguridad son objeto, además, de otras observaciones: además de ser señaladas como inactivas o ineficientes, también son calificadas como corruptas por cuanto se supone que forman parte del entramado delictivo participando del negocio de las drogas y robos, y armando causas judiciales cuando se necesita.

Así, en las coyunturas en las que los gobiernos responden poniendo más fuerzas de seguridad en las calles o dándoles más prerrogativas de manera formal o informal, la repercusión en los barrios es directa. Así, se encuentran barrios donde la generación de jóvenes va cumpliendo el circuito de hostigamiento policial, detenciones más o menos arbitrarias, y así comienza a vincularse con otras instituciones: la justicia y la cárcel.

Por lo general, la justicia avala las actuaciones policiales y se producen encarcelamientos que, desde la perspectiva de la mayoría de los habitantes del barrio, son injustos. Así, encontramos la afirmación frecuente al referirse a los jóvenes: "el que no está preso, está muerto" (Mancini, 2015).

De este modo, la respuesta política al problema de la inseguridad es, en cierta forma, paradójica. Las acciones recaen sobre los barrios populares donde se concentran los habitantes con menos recursos (económicos, sociales y culturales), que con ellos deben enfrentarse a la actuación de las instituciones; como resultado, estos recursos se verán aún más disminuidos. Por eso, ante las situaciones en las que se sufre el accionar de las instituciones punitivas es moneda corriente señalar la falta de inteligencia para hacer frente a la situación.

En paralelo con ese pedido de seguridad en los barrios se teje una trama de saberes sobre las instituciones que regulan la seguridad. En los barrios populares se sostiene la creencia de que cuando los medios de comunicación insisten en un delito de alguien más o menos conocido, la policía hallará pronto un culpable (con más o menos pruebas) entre esos jóvenes señalados siempre como responsables de delitos menores. También se aprende charlando con vecinos sobre las reglas escritas y no escritas de los juzgados y penales para seguirs a un preso.

5. Categoría nativa que remite a llevar a cabo un conjunto diverso de actividades para velar por el bienestar de una persona detenida. 


\title{
Seguir a nuestros presos: el impacto de la cárcel en las familias
}

\begin{abstract}
No puede ser que una madre diga "yo no puedo". No dejen a sus chicos abandonados en una cárcel. No digan "estoy cansada”. No se congelen. Abran neuronas y mentes. Vean que hay organismos que las pueden ayudar, pero no esperen que los organismos las vayan a buscar. Todos ustedes son inteligentes. Todos ustedes son valientes. (Madre de detenido en Encuentro de Familiares de Detenidos, La Plata, comunicación personal, 10.08.2018)
\end{abstract}

Frente a la creciente cantidad de jóvenes encarcelados, son cada vez más las familias que deben acceder a saberes y recursos que permitan seguir al preso. Por ello es imperioso conectar el análisis de la emergencia de estas necesidades con el estudio de la agenda de seguridad, puesto que la inflación carcelaria ubica a una porción significativa de la sociedad en la tarea de asistir a un preso. Como puede suponerse, estas tareas de seguimiento recaen de modo fundamental en las mujeres de las familias: madres, parejas, hermanas o hijas.

Así, suele pesar sobre las mujeres una nueva presión económica por cuanto deberán seguir sosteniendo el hogar, al tiempo que les corresponderá afrontar nuevos gastos para ejercer el cuidado de quien está privado de su libertad. Estas nuevas obligaciones comprenden, cuando menos, viáticos para realizar las visitas, tarjetas de teléfono, comida y elementos de higiene personal; y en el caso de que se opte por un defensor privado, la presión económica puede ser exponencial. Incluso, muchas mujeres relatan un circuito en el que cuando un joven es detenido, algún abogado al que se le supone un arreglo con la comisaría aparece para ofrecer sus servicios. En muchos casos, estos abogados prometen obtener la libertad inmediata a cambio de dinero, que por lo general suele corresponder a sumas excesivas para la situación de las familias. Durante estos años de trabajo de campo hemos escuchado relatos de personas que han vendido sus autos o viviendas, o que se han endeudado para pagar los servicios de abogados que no cumplen esas promesas. Algunos de estos casos pueden observarse en las siguientes notas de campo.

Victoria contó que el hijo está condenado a 11 años. Era primario, entró a robar a un supermercado, pero vino la policía y no pudo robar. Salió y tiró tiros. El abogado le sacó plata y ahora no la atiende. No le dejó firmar el abreviado le dijo que por tanta plata le sacaba al hijo, ella se la juntó y él no lo sacó. Después le pidió más plata [para apelar] y ella se enojó y le dijo que no. (Madre de detenido 1, comunicación personal, 03.03.2017) 
Habla una señora del abogado. No apela porque no tiene más plata, pero el abogado le dice que no importa porque después arregla con el hijo. El problema es que después lo sacan a robar para pagar. Cuenta que el hijo le dice "mi abogado es dios". (Madre de detenido 2, comunicación personal, 25.08.2015)

En muchas ocasiones la situación resulta más complicada puesto que son varias las mujeres preocupadas por el detenido, pero las relaciones entre ellas no son necesariamente de colaboración. Se trata, por el contrario, de situaciones en las que se potencian las tensiones entre suegras y nueras, novias y amantes, o madres e hijas.

Ella tiene problemas con la mujer, por lo cual dejó de ir a verlo. Durante un tiempo alquilaron un departamento en Mar del Plata y vivió con la nuera. Ahora se llevan mal. Se pelearon en una visita y los penitenciarios la criticaron. Ella llora mucho, dijo que está muy deprimida. (Madre de detenido 3, comunicación personal, o8.10.2014)

A la vez que se desarrollan tareas para sostener económicamente el hogar y la supervivencia del preso, el cuidado demanda la realización de otras tareas, entre las que se encuentra, por ejemplo, el seguimiento de la situación legal del detenido: esto último implica adentrarse en la causa y conversar con abogados o defensores oficiales, que no siempre están dispuestos a explicar los pormenores de la situación o a utilizar un lenguaje accesible para quien no conoce la terminología legal básica. Asimismo, en algunos casos hay demandas de parte de la persona privada de su libertad; y las mujeres deben comprender la situación para ser capaces de explicarla al detenido, y contener las ansiedades y frustraciones que ella causa.

No está de más señalar que el acceso a la información de las causas se produce -cuando se logra- en virtud del desplazamiento de las mujeres a los tribunales u oficinas que, por lo general, están ubicados muy lejos de sus residencias. Por lo tanto, este esfuerzo también debe medirse en términos del tiempo y costo económico que implica.

Con lo anterior, muchas mujeres aprenden nuevos lenguajes y adquieren nuevos conocimientos. Como puede apreciarse en la siguiente nota de campo, la opacidad del lenguaje judicial puede llegar al punto de no saberse que alguien ya está condenado tras haber consentido un juicio abreviado.

La defensora oficial no los atiende. Antes tuvieron abogados, pero les sacaron plata y no hicieron nada. Después habla Rosa, que tiene dos hijos presos y uno es epiléptico. El otro acaba de caer, pero firmó un abreviado. Según cuenta Rosa, esta firma es contra su voluntad, pero ya fue sentenciado a 12 años. Entre los papeles que traía, la abogada descifra que la condena está hecha. Eso no lo sabía Rosa. Solo repetía que estaba todo 
mal hecho; que la defensora era un desastre; que se citan como testigos o partícipes a personas que al momento del homicidio estaban presas. (Madre de tres hijos detenidos 1, comunicación personal, 04.08.2015)

El marido de Brenda está en la comisaría. Se peló con un policía y le armaron una causa. Ahora la amenazan cuando le va a llevar comida. El abogado le prometió que saldría en 6 meses con domiciliaria. Lo único que hice fue pagarle a un abogado para que lo condenara. Los obligó a firmar el abreviado. No sabía qué quería decir. Los convenció de que en 6 meses pedirían la domiciliaria. Recién ahora se da cuenta de que es sospechosa la idea de que le van a dar la domiciliaria. (Cónyuge de detenido 1, comunicación personal, 07.09.2017)

Del mismo modo, el bienestar general de los presos y el acceso a derechos mínimos está fuertemente vinculado a la capacidad de las personas que los siguen desde afuera. Así, sus posibilidades de trabajar, estudiar o acceder a servicios de salud (aun cuando se jueguen la vida) pueden depender de las acciones que emprendan las mujeres que los acompañan. Evidentemente, las mujeres deben aprender nuevos lenguajes y saberes. Los mismos no están tipificados a priori ni son del todo accesibles para quien comience a transitar el camino. En el extremo, la vida de los presos puede depender del éxito de las gestiones de sus familiares para protegerlos.

Llama el hijo de Ricardo y él le dice que no se esfuerce para hablar. El pibe ya tiene la orden para ser trasladado a un hospital, pero no consiguen cama; entonces sigue en Magdalena [el penal]. No tienen plata para viajar. El cardiólogo dijo que tiene una infección interna, el pibe tiene fiebre hace una semana. Desde la asociación, llaman a un tipo del comité contra la tortura, le dice que si no hacen algo ahora se nos va a quedar en el camino. La mamá llora.

Ricardo cuenta que al principio no les daban bola, hace 10 días que el chico volvió del hospital a la cárcel y ellos tratan de hacer algo. Desde que se pudieron en contacto con Acifad y ellos con el Comité, ahora hay una defensora que los llama por teléfono, pero el chico sigue ahí, se está muriendo, es desesperante. (Padre de detenido 1, comunicación personal, 11.08.2015)

Al mismo tiempo, las dificultades inherentes a este acompañamiento son tales que en la mayoría de los casos repercuten en la salud de quienes realizan dicha labor; aunque, por lo general, estas consecuencias tienden a ser más explicitadas en aquellas familias en que la cárcel aparece de un modo más o menos sorpresivo.

Mariano no tenía calle, ni siquiera se drogaba. Nosotros no tenemos experiencia. Ya le dije a Mariano que cuando sale nos mudamos y va a ir a un psicólogo. Abro los ojos 
y me duele la cabeza, me voy a dormir y me duele la cabeza. (Madre de detenido 4, comunicación personal, 03.12.2018)

En este punto es preciso destacar que no existe en el Estado ninguna instancia (programa, dependencia u organismo) que se proponga como acompañante de los familiares: el Estado encarcela, a la vez que se exime de responsabilidad por la subsistencia de los presos; pero tampoco asume la responsabilidad de encauzar la ayuda de las mujeres. Al mismo tiempo, los familiares son interpretados desde este universo de lo carcelario como corresponsables de las desviaciones cometidas por los presos, y se les responsabiliza por la reinserción social de los delincuentes cuando cumplen su condena. Todas estas atribuciones deben cumplimentarse en solitario, sin la asistencia de ninguna institución (Ferreccio, 2017; Mancini, 2018; 2019).

Entendemos que esta diversidad de tareas por asumir, así como la complejidad de lenguajes e instituciones que irrumpen en la vida de las personas, pueden resultar intimidantes. Así, en una ocasión, la madre de un joven que había sido confundido con otro y apresado por un delito de notoriedad relataba que la confusión se debía a que la policía había acudido a la casa equivocada, debido a la confusa numeración de la villa de emergencia en la que vivían. La situación del joven era particularmente grave, pues se encontraba en un tratamiento psiquiátrico y sus familiares no podían conseguir que prosiguiera con su medicación hasta que se aclarara la situación. La madre explicaba así el fenómeno:

En el 2010, mi papá tuvo su ACV [accidente cerebrovascular] y a mí la casa se me desbandó. Mi hijo con las drogas. (...) Gratuitamente me la tengo que aguantar porque vivo en ese lugar y porque no tengo plata para pagar un abogado. Me siento atada porque no sé qué puedo hacer. Yo no tengo la inteligencia para hacerme cargo de todo. (Madre de detenido 5, comunicación personal, 06.07.2018)

En este fragmento de entrevista notamos que la madre del joven se responsabiliza, en primer término, por haber estado sobrepasada en un momento de su vida (por los problemas de salud de su padre) en el que su hijo se inició en las drogas. Esta vinculación de su hijo con los estupefacientes lo pone en un estado de conflictividad en el barrio y, junto con otros jóvenes, adquiere la reputación suficiente para ser responsabilizado por cualquier delito, al margen de haber de tomado o no parte en él. Frente a la situación de ver a su hijo detenido de forma injusta y sin posibilidad de suplir sus necesidades en materia de salud, la madre entiende que debe soportar la situación; y que para enfrentar el accionar de las instituciones que injustamente detuvieron a su hijo (cuyo paradero se desconoció por momentos), debería contar con el recurso de una inteligencia mayor. 
En efecto, y como se anotó antes, se señala de forma permanente en la charla de familiares la necesidad de recurrir a la inteligencia para lidiar con estas instituciones. Se trata de enfrentar estos procesos no solo para demostrar la inocencia en el caso en el que sea posible, o para lograr una condena justa; una vez se produce la condena, también es tarea de los familiares seguir al preso para lograr que se ejerzan algunos derechos: estudiar, trabajar, conseguir traslados de ser necesarios por cuestiones de salud o supervivencia, proteger la seguridad del preso, y llevar bienes para el familiar o para evitar que sea herido por otros presos. La gestión de cada una de estas cuestiones requiere conocer nuevos lenguajes, buscar y encontrar información, y hacer seguimiento a los distintos pedidos. Entendemos que lo denominado por las familiares como falta de inteligencia alude a una diferencia en términos de capital cultural (Bourdieu, 200o) que, por momentos, vuelve ininteligible el lenguaje y las razones de las instituciones.

Ahora bien, la inteligencia requerida es compleja puesto que implica tratar con instituciones (justicia u organismos de denuncia), pero también con el sistema de relaciones sociales que tienen lugar dentro de la cárcel y que las familiares deben leer desde afuera de ella. Esto implica saber, por ejemplo, si conviene o no pagar prote ${ }^{6} \mathrm{o}$ llevar ciertos bienes, entre otros asuntos. Entonces, la inteligencia implica también aprender a coordinar estos universos -el entramado de relaciones entre internos y penitenciarios- con el de las instituciones. Un ejemplo del modo en el que operan las intersecciones de estas lógicas es la decisión acerca de la conveniencia o no de solicitar un habeas corpus: en ocasiones, los detenidos piden a sus familiares que lo requieran por temor a su integridad física, aunque a veces también lo solicitan porque estiman mejor pasar a otro lugar de detención; sin embargo, en la práctica este pedido implica un paradero que no es predecible (que podría ser peor que el lugar en el que se encuentra), los riesgos del traslado y la probable pérdida de todos los bienes. En el nuevo penal corresponderá aprender de nuevo las regulaciones de las violencias, usos y costumbres.

Se trata entonces de aprender a combinar -y acaso predecir- y gestionar con mundos sociales que presentan una opacidad para los familiares. Ante esta situación, una de las respuestas posibles es la participación en organizaciones comunitarias que tienen algunos saberes acumulados sobre estos mundos, las cuales permiten transitar este acompañamiento en comunidad.

Como lo señalaba la presidenta de la Asociación de Familiares de detenidos en una entrevista: 
Esto es un tema de supervivencia. Es un tema de estrategia, estás jugando a las cartas todo el tiempo. perdiste una mano, y seguís jugando porque tenés otra. Y lo fundamental es pensar en el que vuelve. (Presidenta de asociación de familiares, comunicación personal, 14.07.2015)

En este contexto puede comprenderse mejor aquello que una madre señalaba en su discurso del encuentro de familiares: promover una búsqueda activa de soluciones y buscar las organizaciones que permitan ayudarlas. Como puede verse en la nota de campo citada más abajo, este acompañamiento es reconocido por las propias participantes de las asociaciones.

Cuenta Lorena (mujer con hermano preso hace s años) que le sonaba el teléfono a las 4 de la mañana y era el hermano para pedirle 1o tarjetas porque estaba apretado. Ella se cansó y dijo basta. Los familiares no tienen que vivir así. Dice que siempre se asesora con Acifad porque dice que así la atienden mejor y cuando habla con los penitenciarios exige que la traten bien. (Hermana de detenido 1, comunicación personal, 01.09.2015)

Ahora bien, por lo general este acercamiento a organizaciones que ayudan a transitar el acompañamiento se produce -cuando ocurre- una vez la persona está detenida (y con toda probabilidad en el momento en el que hay un problema en el juicio, de salud o algún derecho vulnerado). En este sentido, hay una primera instancia en la que se produce la detención en la que muchas personas enfrentan el momento perdiendo recursos económicos: entregan dinero a la policía o a algún abogado que promete tener un arreglo -que luego no se produce- con el juez. Entonces, estos momentos de detenciones constituyen ventanas privilegiadas para la emergencia de negocios informales o ilegales.

Cuando la propuesta política para la emergencia penitenciaria consiste en proponer hacer más cárceles, debemos suponer que estos efectos acabarán por profundizarse; y que no pueden producir otra cosa salvo el agravamiento de las desigualdades sociales, en tanto implican poner en juego los recursos con que se cuenta.

\section{Comentarios finales}

Es importante destacar en este punto algunas conexiones que esbozamos entre los discursos punitivistas, el encarcelamiento masivo y sus efectos extendidos. Aunque no pueda establecerse una conexión inmediata entre sentimiento de inseguridad y demandas de orden, existe un descontento social y le cabe a cada gobierno darle respuesta. 
Como se señaló, el gobierno de Mauricio Macri (2015-2019) se caracterizó por desenvolverse con comodidad en retóricas punitivas y, si bien los cambios en materia de seguridad pueden no haber sido tan drásticos, fueron registrados por la población. En este sentido, nuestros trabajos de campo dieron cuenta de que los sectores sociales menos favorecidos se consideran los principales afectados por estas dinámicas de incremento de los controles de seguridad. En esa medida, el incremento del encarcelamiento presentado por el gobierno como una respuesta a la lucha por del delito afecta de modo primordial a estos sectores, con lo cual es posible encontrar en los barrios populares una superposición de tramas barriales y carcelarias.

Ahora bien, las libertades civiles erosionadas no son solo las de aquellos jóvenes, pobres, varones, que el sistema penal selecciona para su detención; también es afectada la libertad de las mujeres familiares que siguen a esos presos. En este proceso se profundizan las diferencias sociales, puesto que las personas con menos recursos materiales, culturales y simbólicos se encuentran ante la necesidad de enfrentar una superposición de lógicas (judicial, carcelaria) difíciles de leer para procurar el bienestar de su familiar.

En este contexto es posible encontrar la emergencia de procesos comunitarios que implican una resistencia subjetiva a estas dinámicas. Si bien estas organizaciones incipientes están atravesadas también por múltiples desigualdades y dificultades, se configuran como ámbitos de reconocimiento y refugio para afrontar las dificultades cotidianas.

\section{Referencias}

Bauman, Zygmunt (1999). La globalización. Consecuencias humanas. Buenos Aires: FCE.

Bourdieu, Pierre (2000). Cosas dichas. Buenos Aires: Gedisa.

Ferreccio, Vanina (2017). La larga sombra de la prisión. Una etnografia de los efectos extendidos del encarcelamiento. Buenos Aires: Paidós.

Focas, Brenda; Galar, Santiago (2019). El regreso de las víctimas. Reconfiguraciones en el procesamiento público de la inseguridad en la actual coyuntura política nacional (2016-2017). Austral Comunicación, 8(1), 131-150.

Infobae (2019). El Gobierno declaró la emergencia penitenciaria por la superpoblación en las cárceles. Recuperado de https://www.infobae.com/politica/2019/o3/25/el-gobierno-declaro-la-emergencia-penitenciaria-por-la-superpoblacion-de-las-carceles/ 
Kessler, Gabriel (2009). El sentimiento de inseguridad. Sociología del temor al delito. Buenos Aires: Siglo XXI.

Kessler, Gabriel (2011). La extensión del sentimiento de inseguridad en América Latina: relatos acciones y políticas en el caso argentino. Sociología Política 19(40), 83-97.

Lancaster, Roger (2011). Republic of Fear: The Rise of Punitive Governance in America. The Insecure American: How We Got Here and What We Should Do About It (pp. 63-76), editado por Hugh Gusterson y Catherine Besteman. Berkeley: University of California Press.

Mancini, Inés (2015). Prevención social del delito. Relaciones entre agentes estatales y jóvenes de sectores populares. San Martín: UNSAM.

Mancini, Inés (abril, 2018). La Asociación Civil de Familiares de Detenidos (Acifad). Interaccionesy articulaciones entre actores vinculados a la vida en las cárceles argentinas: un sentir colectivo que reclama atención. Ponencia presentada en Seminario Internacional "Gobierno, conflictos y resistencias en las prisiones de América Latina”, Recife, Brasil.

Mancini, Inés (2019). Medios de comunicación y formas de sociabilidad en circuitos carcelarios de la Argentina. Sociedad, 39, 145-159.

Mancini, Inés; Rey, Julieta (abril, 2017). Delitos, violencias e instituciones en una villa de la provincia de Buenos Aires: demandas y respuesta de las fuerzas de seguridad. Ponencia presentada en las I Jornadas de Estudios Sociales sobre Delito, Violencia y Policía, Universidad Nacional de La Plata, Argentina.

Mathiesen, Thomas (2003). Juicio a la prisión. Buenos Aires: Ediar.

Melossi, Dario (20018) Controlar el delito, controlar la sociedad. Teoríasy debates sobre la cuestión criminal, del siglo XVIII al XXI. Buenos Aires: Siglo XXI.

Pereyra Iraola, Victoria (2017) (In)movilidades en torno al espacio carcelario: relaciones de género y gobernabilidad en cárceles federales en Buenos Aires, Argentina. Revista Transporte y Territorio, 16, 93-111.

Sozzo, Máximo (2007). ¿Metamorfosis de la prisión? Proyecto normalizador, populismo punitivo y "prisión depósito" en Argentina. Urvio. Revista Latinoamericana de Seguridad Ciudadana, 1, 88-116.

Sozzo, Máximo (2016). Postneoliberalismoy penalidad en América del Sur. Buenos Aires: Clacso.

Tonkonoff, Sergio (2012). La cuestión criminal. Ensayo de (re)definición. Nómadas. Revista Crítica de Ciencias Sociales y Jurídicas, 35, 201-221.

Vázquez, Melina (2015). Juventudes, políticas públicas y participación. Un estudio de las producciones socioestatales de la juventud. Buenos Aires: Grupo Editor Universitario. 